\title{
A cross-city molecular biogeographic investigation of arbuscular mycorrhizas in Conyza canadensis rhizosphere across native and non-native regions
}

\author{
Manzoor A Shah' ${ }^{1 *}$, Marie-Eve Beaulieu' ${ }^{2}$ Zafar A Reshi ${ }^{1}$, Salman Qureshi ${ }^{3}$ and Damase P Khasa ${ }^{2}$
}

\begin{abstract}
Introduction: The ecological processes underlying the suppressive impacts of invasive species on native species diversity, both above- and below-ground, in non-native regions are not well understood. We therefore aimed to investigate the cross-city biogeographic patterns of arbuscular mycorrhizal (AM) diversity in Conyza canadensis rhizosphere in native (North American) and non-native (Kashmir Himalayan) regions.

Methods: We recovered AMF spores from rhizospheric soils of Conyza in native and non-native ranges, besides doing so from the uninvaded sites in the introduced region. DNA extracted from AMF spores was processed for cloning and PCR-RFLP of SSU rRNA gene to yield the restriction groups (RGs) followed by their sequence analysis to determine the sequence groups (SGs).

Results: The results indicated greater diversity of RGs and SGs in Conyza rhizosphere in native than in non-native sites. In the introduced region, however, the AMF diversity was more in uninvaded than in invaded sites. The species composition of AMF varied significantly between native and non-native regions and so also between invaded and uninvaded habitats.

Conclusions: Though difference in AMF diversity between Conyza invaded and uninvaded sites may be attributed to invasion, the role of other evolutionary factors seems likely for differences between the native and non-native regions. We suggest that the ecological processes underlying these evolutionary differences in two biogeographic regions, besides the intensity of urbanization, might play some role in these differences.
\end{abstract}

Keywords: Mycorrhizal symbiosis; Conyza canadensis; Evolution; Kashmir Himalaya; North America; Plant invasion; Urbanization

\section{Introduction}

Arbuscular mycorrhizal symbiosis in view of its central role in plant-rhizosphere interactive dynamics is referred as the mother of plant root endosymbioses (Parniske 2008). These AMF may act as drivers of various ecological processes (Shah et al. 2009). The different mechanisms through which these fungi influence or are influenced by various ecological processes have been reviewed (Bonfante and Genre 2010). Urbanization and ensuing

\footnotetext{
* Correspondence: mashah75@yahoo.com

'Department of Botany, University of Kashmir, Srinagar-190 006, Jammu and Kashmir, India

Full list of author information is available at the end of the article
}

disturbances generally facilitate invasion by alien species (Dar et al. 2015) thereby causing decline in richness of plant communities.

The scarce information available on the effect of alien plants on AM community dynamics calls for more research. However, understanding the impact of plant invasions on mycorrhizal diversity, an emerging challenge for contemporary ecologists, is beset with complexities not only due to the simultaneous operation of a multitude of biotic and abiotic factors at different eco-evolutionary scales (Shah et al. 2009) but also due to technical, methodological, and conceptual reasons (Green and Bohannan 2006). Many AM fungi are difficult to identify using 
exclusively either morphological characteristics or molecular criteria, and they are difficult to culture in the absence of a host plant and possess multiple and slightly different variants of the nuclear-encoded ribosomal RNA gene within single spores (Sanders et al. 1995; Lanfranco et al. 1999).

The effect of plant invasions on the homogenization of aboveground native biodiversity is reasonably well studied; both in aquatic and terrestrial systems (e.g., McKinney and Lockwood 1999; McKinney 2004; Rooney et al. 2004; Taylor et al. 2004; Shah et al. 2014). However, the impact of invasive plants on structurally and functionally diverse native soil communities remains largely unknown. Evidence suggests that biological invaders can generally promote positive feedback involving soil microbes (Scott et al. 2001; Callaway et al. 2004; Wolfe and Klironomos 2005; Reinhart and Callaway 2006) and mycorrhizas (Eppstein and Molofsky 2007; Shah and Reshi 2007; Shah et al. 2008a, b), and such feedbacks may promote invasiveness. Some invasive species in turn may negatively influence diversity of AMF (Shah et al. 2010), one of the important drivers of plant diversity and productivity (van der Heijden et al. 1998; Burrows and Pfleger 2002).

Conyza canadensis (L.) Cronq. (Canadian horseweed) is an annual, herbaceous member of sunflower family (Asteraceae), native to North America and invasive in a number of countries, including Kashmir Himalaya, India. It was introduced into Europe from North America almost 300 years ago, where it completely naturalized and became one of the most abundant plant species (Thebaud and Abbott 1995) especially in urban and semiurban habitats (Shah et al. 2014). Owing to the British colonial past of India, C. canadensis was most likely introduced to Kashmir Himalaya through Europe as the species was reportedly one of the six earliest and most abundant weeds in London during World War II (Salisbury 1942). The rapid range expansion of this ruderal species is attributed to production of a large number of small, wind-dispersed seeds (over 200,000 seeds per plant), high resistance to diseases and herbicides (Weaver 2001), besides its association with
AM mutualists (Shah et al. 2010). A recent transcontinental study revealed that $C$. canadensis strongly suppresses native plant diversity in non-native regions but not in its native range (Shah et al. 2014). In the present study, we asked whether the AMF diversity differs in Conyza rhizosphere in native and non-native ranges and tackled this question through a molecular biogeographic approach.

\section{Methods}

\section{Sample collection and sampling site description}

Soil samples were collected from six sites, three each in Kashmir Himalaya (South Asia) and Canada (North America). A brief description of the study sites in both regions is given in Table 1. The Kashmir Himalayan sites were highly invaded by $C$. canadensis and soil samples drawn from each of these sites and nearby similar uninvaded (control) sites were transported to the Centre of Forestry Research, University Laval, Quebec, Canada, for analysis. The invaded and uninvaded sites in Kashmir Himalaya were $10 \mathrm{~m}$ apart from each other. While $C$. canadensis formed almost dense monocultures in Kashmir Himalaya, it occurred quite sparsely in the North American sites. Hence, it was not possible to have uninvaded (control) sites in native region the way we had them in invaded region. Rhizospheric soils of $C$. canadensis were collected from all the North American sites in Quebec on the same day and stored at $-20^{\circ} \mathrm{C}$ prior to analysis. The sites varied in the disturbance regimes, light exposure, and geographical coordinates (Table 1). We took ten rhizospheric soil samples per site approximately at a distance of $1 \mathrm{~m}$ from each other. Three replicates of each sample were processed for analysis. Soil samples were collected in both the regions from the rhizospheres of $C$. canadensis individuals varying from seedling stage through pre-flowering to post-flowering stages.

\section{AMF spore isolation}

Arbuscular mycorrhizal fungal spores were isolated from all the soil samples using standard wet sieving and sucrose centrifugation procedure (Daniels and Skipper

\section{Table 1 Brief description of sampling sites in Kashmir Himalaya and North America}

\begin{tabular}{|c|c|c|c|c|c|}
\hline Site & Habitat type and land-use pattern & Latitude & Longitude & Altitude (m) & $\mathrm{pH}$ \\
\hline \multicolumn{6}{|c|}{ Kashmir Himalayan sites } \\
\hline Lalbazar & Dry, exposed, highly disturbed, typical urban, dense Conyza cover & $34^{\circ}-5^{\prime} \mathrm{N}$ & $74^{\circ}-50^{\prime} \mathrm{E}$ & 1,584 & 6.84 \\
\hline Zakura & Dry, exposed, moderately disturbed, urban, dense Conyza cover & $34^{\circ}-5^{\prime} \mathrm{N}$ & $74^{\circ}-50^{\prime} \mathrm{E}$ & 1,587 & 7.33 \\
\hline Nagbal & Dry, protected, undisturbed, semi-urban, dense Conyza cover & $34^{\circ}-18^{\prime} N$ & $74^{\circ}-56^{\prime} \mathrm{E}$ & 1,586 & 7.70 \\
\hline \multicolumn{6}{|l|}{ North American sites } \\
\hline Rivière St-Charles & Dry, exposed, less disturbed, semi urban, sparse Conyza cover & $46^{\circ}-48^{\prime} N$ & $71^{\circ}-15^{\prime} \mathrm{W}$ & 3 & 7.51 \\
\hline Rivière Jaune & Dry, exposed, semi urban, sparse Conyza cover & $46^{\circ}-54^{\prime} N$ & $71^{\circ}-19^{\prime} \mathrm{W}$ & 158 & 7.65 \\
\hline Lac Clément & Dry, exposed, urban, sparse Conyza cover & $46^{\circ}-56^{\prime} N$ & $71^{\circ}-21^{\prime} \mathrm{W}$ & 215 & 6.46 \\
\hline
\end{tabular}

Table shows habitat type, geographical coordinates, and soil $\mathrm{pH}$. 
1982; Tommerup 1992). A $30 \mathrm{~g}$ air-dried soil sample was thoroughly washed through a set of sieves (mesh size $\mu \mathrm{m}$ : 250, 106, 75, and 53). Sievings were collected and centrifuged at 2,000 rpm for $5 \mathrm{~min}$, and the pellet was resuspended in $25 \mathrm{ml}$ of $50 \%$ sucrose and centrifuged again for $2 \mathrm{~min}$ at the same speed. The spores in the supernatant were washed, and sucrose was removed by a vacuum filtration system. Only the live viable spores, separated from dead spores under a stereo microscope, were used for DNA extraction. About 100 spores from each sample were picked up under the stereo microscope and placed in $1.5-\mathrm{ml}$ tubes for DNA extraction.

\section{DNA extraction}

DNA from AMF spores was extracted by the Chelex method as described by Simon (1996) with some modifications. Spores representing the whole range of morphological diversity were placed in Eppendorf tube with $50 \mu \mathrm{L}$ of distilled water and crushed with blue pestles before and after adding $50 \mu \mathrm{L}$ of $20 \%$ Chelex-100. Then, the samples were incubated at $85^{\circ} \mathrm{C}$ for 3 min followed by a short vortex and incubation in ice for $5 \mathrm{~min}$. This heating-cooling cycle was repeated twice; and subsequently, the samples were incubated at $60^{\circ} \mathrm{C}$ for $90 \mathrm{~min}$ followed by centrifugation at 13,000 rpm for $5 \mathrm{~min}$. The supernatant was collected and immediately processed for PCR amplification. The samples were stored at $-80^{\circ} \mathrm{C}$ until used in subsequent molecular analysis.

\section{PCR amplification}

From the total AMF DNA, only the portion of the SSU rRNA gene was specifically amplified using the universal eukaryotic primer NS31 (Simon et al. 1992) and the AMF specific primer AM1 (Helgason et al. 1999). The master mix for each PCR reaction was composed of Feldan Bio kit (Feldan Bio, Québec, QC, Canada) with 1 unit of taq, $0.5 \mu \mathrm{M}$ of each primer, $0.2 \mathrm{mM}$ of dNTP, and $1 \mu \mathrm{l}$ of total AM DNA. The PCR reaction was performed in a MJ Research PTC-225 Peltier Thermal Cycler as follows: (i) initial denaturation step (4 $\mathrm{min}$ at $94^{\circ} \mathrm{C}$ ), (ii) 35 cycles of denaturation $\left(50 \mathrm{~s}\right.$ at $\left.94^{\circ} \mathrm{C}\right)$ followed by annealing $\left(1 \mathrm{~min}\right.$ at $\left.59^{\circ} \mathrm{C}\right)$ and elongation $\left(2 \mathrm{~min}\right.$ at $\left.72^{\circ} \mathrm{C}\right)$, and (iii) final elongation step $(10 \mathrm{~min}$ at $72^{\circ} \mathrm{C}$ ). The PCR products were purified using QIAquick PCR Purification kit (QIAGEN, Toronto, ON, Canada) following the manufacturer's protocol. The purified PCR products were quantified in $1 \%$ agarose gel.

\section{Cloning, amplification, and restriction digestion}

About $75 \mathrm{ng}$ of purified PCR products were cloned using the pGEM $^{\circ}-\mathrm{T}$ Easy Vector Systems (Promega Corporation, Madison, WI, USA) according to the manufacturer's instructions. For each sample, 96 cloned products were randomly selected, and then PCR was performed for each of the cloned products using the M13 universal primer set. PCR amplification for transformant DNA was performed, as above, using a MJ Research PTC-225 Peltier Thermal Cycler with following modification of 30 cycles, with one step consisting of denaturation $\left(50 \mathrm{~s}\right.$ at $\left.94^{\circ} \mathrm{C}\right)$, annealing $\left(50 \mathrm{~s}\right.$ at $\left.55^{\circ} \mathrm{C}\right)$, and elongation $\left(1 \mathrm{~min}\right.$ at $\left.72^{\circ} \mathrm{C}\right)$. The PCR products were digested independently with HinfI and AluI according to the manufacturer's instructions (New England Biolabs, Ipswich, MA, USA). The pattern of restriction length polymorphism (RFLP) was observed by running $2 \%$ agarose plus $1 \%$ Synergel. After analyzing the restriction fragment length polymorphism (RFLP) pattern manually and with Genetools version 4.0 (Syngene, Frederick, MD, USA) and grouping clones with similar pattern in RFLP type or restriction groups (hereafter RG), at least three clones of each RFLP type (RGs) were sequenced (Plate-forme d'Analyses Génomiques de 1' Université Laval, Québec, QC, Canada) on a ABI 16capillary genetic analyzers 3130XL (Applied Biosystems, Foster City, CA, USA) to verify homogeneity of the RG and subsequent analysis. Because three restriction groups were not homogenous, we used alternative restriction endonucleases to distinguish the different subgroups. For RG1 RsaI enzyme was used; and for RG11 and RG19, ClaI enzyme served to distinguish the different subgroups.

\section{Grouping and phylogenetic analysis}

DNA sequences were edited with BioEdit version 7.0.5 (http://www.mbio.ncsu.edu/BioEdit/bioedit.html; Hall 1999). Sequences with more than $5 \%$ of 'N' were not included in the subsequent analyses. The BLASTn algorithm (http://www.ncbi.nlm.nih.gov/BLAST/) was used to query GenBank (NCBI) for highly similar sequences. The sequences not corresponding to the mycorrhizal species were discarded. The sequences retained were used to precisely analyze the RG grouping. Many RGs yielded the same sequence, so they were grouped together to give a new grouping pattern, the sequence groups (hereafter SGs). Sequences were also used for phylogenetic analyses. They were aligned with ClustalX version 1.81 (ftp://ftpigbmc.u-strasbg.fr/pub/ClustalX/; Thompson et al. 1997). Neighbor-joining (Kimura-2 parameters model) and maximum parsimony (search with heuristic method closesneighbor-interchange CNI with 100 random stepwise addition replicates) phylogenetic analyses were carried out with MEGA4.1 (http://www.megasoftware.net/ Tamura et al. 2007). All analyses were followed by a 1,000 bootstrap replicates. Bayesian inference of phylogeny was calculated with MrBayes program, assuming a $4 \times 4$ model and non-variable substitution rates among sites - gamma rates. Analyses were based on two runs of four Markov chain Monte Carlo analyses where 2,000,000 generations were generated, burn-in at 0.5 rate, and sampled every 
100 generations for a total of 10,001 trees generated (http://mrbayes.csit.fsu.edu/ Ronquist and Huelsenbeck 2003). Phylogenetic affiliation for all the sequence identifications was based on $98 \%$ to $99 \%$ similarity. The sequences were deposited in the GenBank vide voucher numbers (suite.sqn IAMF1-18 HQ712058; IAMFC2-01 HQ712059; IAMFC2-46 HQ712060; IAMFC1-08 HQ71 2061; IAMF2-108 HQ712062; IAMF1-74 HQ712063).

\section{Statistical analysis and diversity indices}

Two types of analyses were carried out, one for AMF diversity and other for the resemblance between the AMF species composition across different sites. Simpson $(D)$, Shannon-Wiener $(H)$, and Pielou's evenness $(E)$ diversity indices were used to evaluate the diversity of AMF restriction and sequence $+g$-"*roups. A multivariate analysis (correspondence analysis) was done to verify resemblance between the communities. Rarefaction and coverage $(C)$, where $C$ is defined by the equation: $C=1-$ $(\mathrm{n} 1 / N), \mathrm{n} 1$ is the number of clones that occurred only once (frequency $=1$ ), and $N$ is the total number of clones examined of species richness, were used to confirm the sufficiency of sampling effort. Various indices and correspondence analyses were computed in $\mathrm{R}$ with the vegan package (R Development Core Team. 2010. R: A language and environment for statistical computing. R Foundation for Statistical Computing, Vienna, Austria. ISBN 3-900051-07-0, URL http://www.R-project.org/).

\section{Results}

The sites invaded by C. canadensis in Kashmir Himalaya from which soil samples were drawn represented almost monospecific stands, as opposed to the control (uninvaded) sites in the Kashmir as well as the native North American sites where about seven to ten other species occurred at each site. The species co-occurring with $C$. canadensis in North American region included Artemisia frigida, Aster falcatus, Chrysopsis villosa, Elymus cinerius, Festuca scabrella, Festuca idahoensis, Monarda fistulosa, Potentilla argentea, and Vulpia octoflora. The species usually occurring in uninvaded control sites in Kashmir Himalaya included Arctium lappa, Bromus japonicas, Chenopodium album, Convolvulus arvensis, Medicago polymorpha, Potentilla nepalensis, Polygonum hydropiper, Steria viridis, Sisymbrium loselli, and Solanum nigrum. While the average $\mathrm{pH}$ of both invaded and uninvaded sites in Kashmir Himalaya was 7.29, for North American sites it was 7.20. Template DNA, extracted from AMF spores recovered from field collected soils, yielded enough PCR products for each sample for subsequent analyses. Adequate number of clones for each sample was processed, in terms of the percent coverage and rarefaction indices (Table 2), to reflect the AMF diversity.

The pattern of restriction digestion, reflective of AMF diversity, revealed evident differences across biogeographical regions. While the extent of occurrence of restriction groups (RGs) varied in C. canadensis invaded samples from native and invaded regions, the two regions also shared some RGs. Representatives of each RG were sequenced resulting in 12 different sequence groups (Table 2). In many cases, different RGs yielded the same sequence and they were grouped together as one sequence group (SG). Blasting of representative sequences into GenBank databases led to characterization of most of the sequences to the species level, though few were identified to the genus level only (Figure 1). Glomus was the dominant genus across the samples. The only AM species common between North American and Kashmir Himalayan samples included Glomus caledonium and G. constrictum. The species found exclusively in North American samples included Glomus sp., G. etunicatum, G. versiforme, and

Table 2 Comparison of AMF partial SSU rRNA gene library composition from replicate soil samples of Conyza canadensis

\begin{tabular}{|c|c|c|c|c|c|c|}
\hline $\begin{array}{l}\text { Clone library } \\
\text { and soil samples }\end{array}$ & $\begin{array}{l}\text { Number } \\
\text { of clones }\end{array}$ & $\begin{array}{l}\text { Number } \\
\text { of SGs }\end{array}$ & $\begin{array}{l}\text { Number of SGs } \\
\text { uniqueto library }\end{array}$ & Percentcoverage $^{a}$ & $\begin{array}{l}\text { Number of SGs found in at } \\
\text { least two libraries in the same system }\end{array}$ & $\begin{array}{c}\text { Rarefaction for } \\
\text { number of clones }\end{array}$ \\
\hline QAMF2 & 43 & 4 & 0 & 100 & 4 & $3.8(35)$ \\
\hline QAMF 3 & 44 & 5 & 1 & 97.7 & 4 & $4.4(35)$ \\
\hline QAMF4 & 48 & 5 & 2 & 95.8 & 3 & $4.7(35)$ \\
\hline IAMF1 & 43 & 4 & 1 & 95.7 & 3 & $3.8(35$ \\
\hline IAMF2 & 39 & 2 & 0 & 100 & 2 & $2.0(35)$ \\
\hline IAMF3 & 39 & 3 & 1 & 97.4 & 2 & $3.0(35)$ \\
\hline IAMFC1 & 90 & 3 & 2 & 97.8 & 1 & $2.6(35)$ \\
\hline IAMFC2 & 86 & 2 & 0 & 100 & 1 & $1.9(35)$ \\
\hline
\end{tabular}

Drawn from native North American (QAMF) and introduced Kashmir Himalayan (IAMF) regions with reference to uninvaded control samples (IAMFC) in the

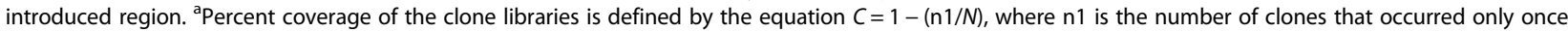
(frequency $=1$ ), and $N$ is the total number of clones examined (Good, I.L. 1953. The population frequencies of species and the estimation of population parameters. Biometrika 40, 237-264). ${ }^{\mathrm{b}}$ Rarefaction predicts the diversity that would probably be observed in sample of reduced size (Foote, M. 1992. Rarefaction analysis of morphological and taxonomic diversity. Paleobiology 18, 1-16). 


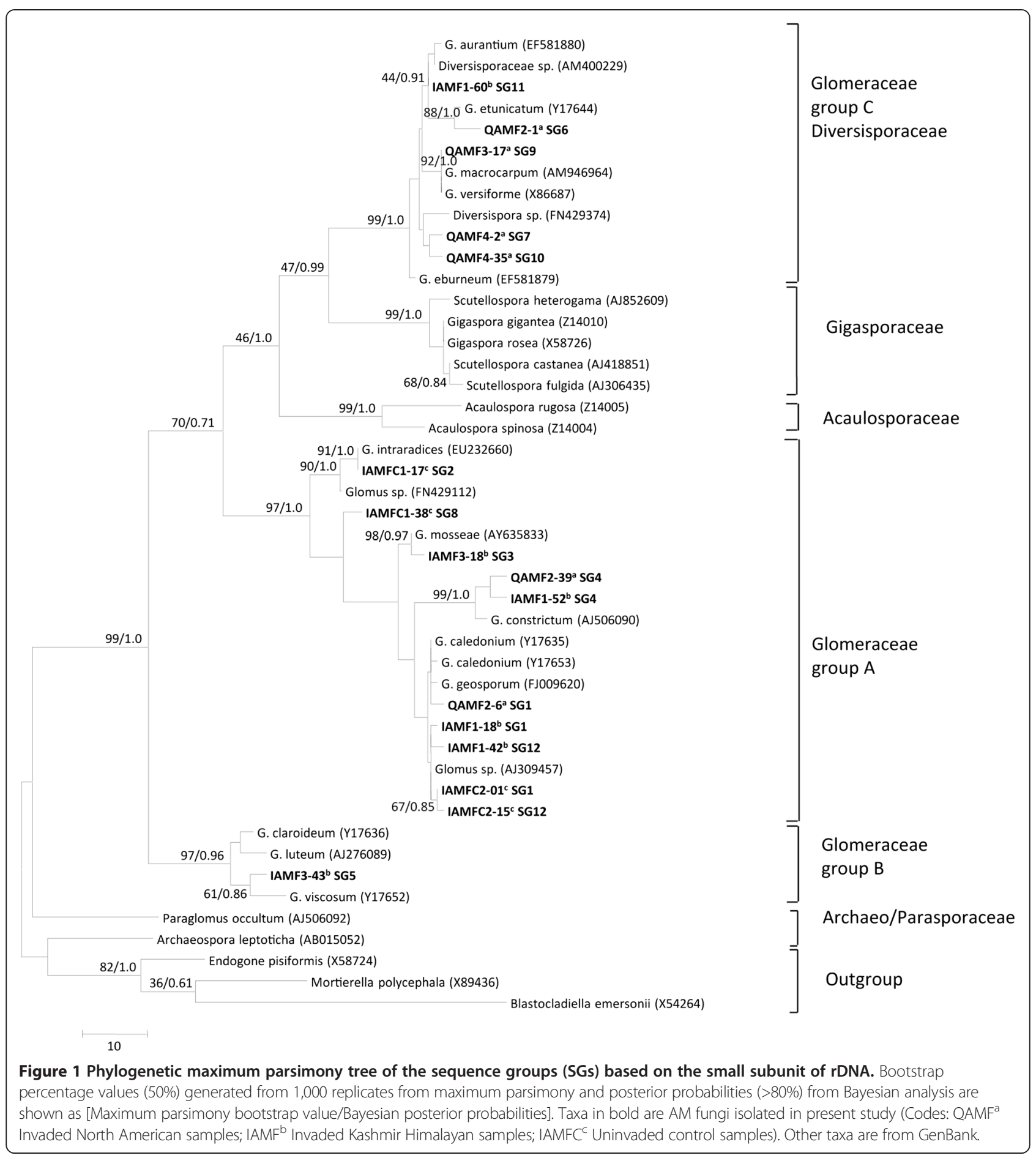

Diversispora sp. A specific isolate of Glomus sp., G. claroideum, and a member of Diversisporaceae were exclusively found in invaded samples. Another specific isolate of Glomus sp. and G. intraradices were the only species exclusively found in the control samples. Glomus caledonium was the species common to all the investigated samples.
Diversity indices of AMF were higher in the North American than in the Kashmir Himalayan samples (Table 3). Comparison of Shannon-Wiener and Simpson's diversity indices showed relatively higher diversity values for Kashmir soils not invaded by C. canadensis than for soils invaded by it (Table 3). More so, average AMF diversity in uninvaded soil samples in Kashmir 


\section{Table 3 Frequency of occurrence and diversity indices for the sequence groups (SGs)}

\begin{tabular}{|c|c|c|c|c|c|c|c|c|c|c|c|c|c|c|}
\hline $\begin{array}{l}\text { Sequence } \\
\text { groups (SG) }\end{array}$ & $\begin{array}{c}\text { Closest relative } \\
\text { found In GenBank }\end{array}$ & \% Similarity & QAMF2 & QAMF3 & QAMF4 & QAMF Average & IAMF1 & IAMF2 & IAMF3 & IAMF Average & IAMFC1 & IAMFC2 & IAMFC3 & IAMFC Average \\
\hline 1 & Glomus caledonium Y17636 & 99 & 17 & 21 & 15 & 17.7 & 37 & 37 & 35 & 36.3 & 50 & 82 & 0 & 44.0 \\
\hline 2 & G. intraradices EU23266 & 99 & 0 & 0 & 0 & 0.0 & 0 & 0 & 0 & 0.0 & 38 & 0 & 0 & 12.7 \\
\hline 3 & G. mosseae AJ55616 & 99 & 0 & 0 & 0 & 0.0 & 0 & 0 & 2 & 0.7 & 0 & 0 & 0 & 0.0 \\
\hline 4 & G. constrictum AJ569 & 98 & 1 & 1 & 20 & 7.3 & 3 & 2 & 0 & 1.7 & 0 & 0 & 0 & 0.0 \\
\hline 5 & G. claroideum Y17636 & 98 & 0 & 0 & 0 & 0.0 & 0 & 1 & 4 & 1.7 & 0 & 0 & 0 & 0.0 \\
\hline 6 & G. cf. etunicatum Y17644 & 99 & 24 & 14 & 1 & 13.0 & 0 & 0 & 0 & 0.0 & 0 & 0 & 0 & 0.0 \\
\hline 7 & G. eburneum EF581879 & 99 & 0 & 0 & 11 & 3.7 & 0 & 0 & 0 & 0.0 & 0 & 0 & 0 & 0.0 \\
\hline 8 & Glomus sp. FN429112 & 99 & 0 & 0 & 0 & 0.0 & 0 & 0 & 0 & 0.0 & 2 & 0 & 0 & 0.7 \\
\hline 9 & G. versiforme X86687 & 99 & 0 & 8 & 0 & 2.7 & 0 & 0 & 0 & 0.0 & 0 & 0 & 0 & 0.0 \\
\hline 10 & Diversispora sp. FN429374 & 98 & 0 & 0 & 1 & 0.3 & 0 & 0 & 0 & 0.0 & 0 & 0 & 0 & 0.0 \\
\hline 11 & Diversisporaceae sp. AM400229 & 99 & 0 & 0 & 0 & 0.0 & 1 & 0 & 0 & 0.3 & 0 & 0 & 0 & 0.0 \\
\hline \multirow[t]{6}{*}{12} & Glomus sp. AJ309457 & 99 & 0 & 0 & 0 & 0.0 & 2 & 0 & 0 & 0.7 & 0 & 4 & 0 & 1.3 \\
\hline & TOTAL & & 42 & 44 & 48 & 44.667 & 43 & 40 & 41 & 46 & 90 & 86 & 0 & 88 \\
\hline & & & & & & Average & & & & Average & & & & Average \\
\hline & Shannon $(H)$ & & 0.7749 & 1.1133 & 1.2272 & 1.4104 & 0.5452 & 0.3141 & 0.5095 & 0.6001 & 0.7752 & 0.1881 & 0.0000 & 0.6903 \\
\hline & Pielou's evenness $(E)$ & & 0.7053 & 0.8031 & 0.7625 & 0.8763 & 0.3933 & 0.2859 & 0.4637 & 0.3728 & 0.7056 & 0.2714 & 0.0000 & 0.4979 \\
\hline & Simpson (D) & & 0.5091 & 0.6374 & 0.6753 & 0.7200 & 0.2520 & 0.1413 & 0.2594 & 0.2596 & 0.5126 & 0.0887 & 1.0000 & 0.3947 \\
\hline
\end{tabular}

Based on the small subunit of rDNA of AMF from native (QAMF), invaded (IAMF), and control (IAMFC) samples. 
Himalaya was lower than the average diversity of the samples drawn from native range of $C$. canadensis (Table 3). Correspondence analyses (CA) for both RGs revealed closer relationships among North American AMF taxa than between North American and Kashmir AMF, from either control or invaded soils (Figure 2). However, CA showed that Kashmir samples invaded by C. canadensis are more similar to Kashmir control samples, in comparison to the North American samples. In other words, more similarity between AMF species of control vs. invaded soils in the non-native region, in comparison with native region samples, was brought out by the correspondence analyses of RGs (Figure 2). The CA plot for SGs yielded almost the similar trend to that of RGs.

\section{Discussion}

Our results indicate that the homogeneity or heterogeneity of aboveground plant communities can potentially influence soil microbial communities as indicated by some earlier studies (see for instance van der Heijden et al. 1998). It seems that relatively less species richness of plants that co-occur with Conyza canadensis in nonnative ranges than in its native range (Shah et al. 2014) may possibly contribute partly to less mycorrhizal species diversity in Conyza invaded plots. In other words, suppression of the native plant diversity by Con$y z a$ in non-native ranges may possibly be through its negative effects on the symbiotic association between AM fungi and native plants the way it has been recently demonstrated in case of Impatiens glandulifera (Ruckli et al. 2014). Decreases in AMF species richness due to plant invasion has been previously reported by other workers (Burrows and Pfleger 2002; Mummey and Rillig 2006). The less diversity of AMF in Conyza invaded than those in uninvaded urban sites on morphological grounds reported earlier (Shah et al. 2010) seems to be rather confirmed by the use of molecular approaches in the present study. Notwithstanding the problems associated with the SSU rRNA heterogeneity in identification of different isolates of the same AMF species, strength of this molecular marker for community profiling stands proved beyond doubt (Stéphani and Bérubé 2006). The PCR-RFLP rRNA markers coupled with cloning are reliable, easily reproducible, and quite efficient for AM community analysis. It has been observed that richer plant communities support greater AM species richness (Eom et al. 2000; Burrows and Pfleger 2002; Husband et al. 2002), and positive relationships between the diversity of plants and diversity of AMF have been shown

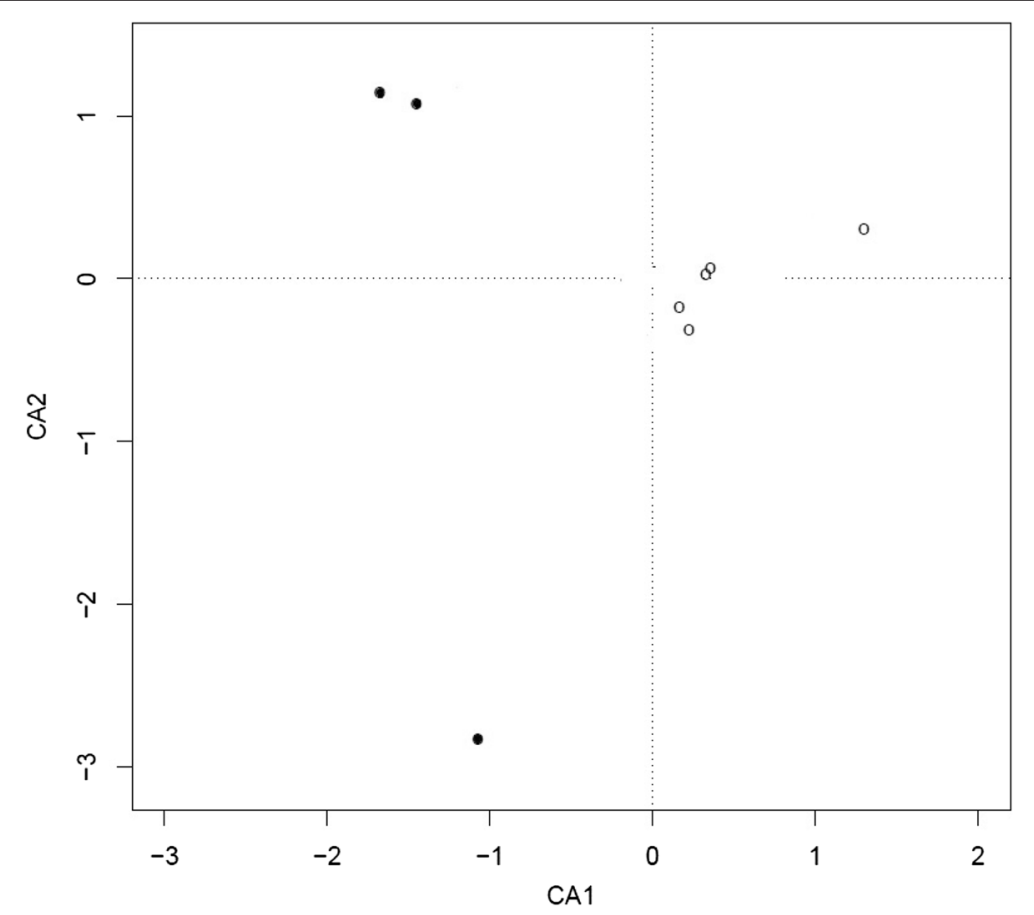

Figure 2 Correspondence analysis of the different soil samples according to the frequency of associated AM fungi. Correspondence analysis of the different soil samples according to the frequency of associated AM fungi characterized with the restriction digestion method (RG). Soil samples are positioned along the first two DA axes, where Eigenvalues are 0.5515 for CA1 and 0.5055 for CA2. Black circles represent North American (QAMF) samples and white circles represent Kashmir Himalayan (IAMF) samples. The CA plot for SGs yielded almost the similar trend to that of RGs. 
(Grime et al. 1987; van der Heijden et al. 1998). Lower AM diversity in the Conyza invaded than those in uninvaded soils could therefore be partly due to relatively diverse aboveground plant cover in native sites as well as in uninvaded sites in Kashmir Himalaya as against almost the monospecific stands of Conyza invaded plots. Such a shift in AMF diversity may potentially have significant influence on both above- and belowground biodiversity. Moreover, changes in the soil chemistry are also expected when aboveground plant communities change from more diverse and heterogeneous to homogenous due to plant invasions (Vitousek and Walker 1989; Fierer et al. 2009). The differences in $\mathrm{NO}_{3}$ and $\mathrm{K}$ and smaller but nevertheless real differences in $\mathrm{P}$ between invaded and uninvaded sites (data not presented) could per se explain the differences in AMF community. But whether such differences in soil nutrient characteristics are directly attributable to Conyza abundance also remains to be seen. The decline in AMF diversity due to invasion by allelopathic Conyza (Shaukat et al. 2003) draws support also from Callaway et al. (2008), who reported that through novel weapons invasive plants can suppress fungal mutualists in invaded but not in native range.

The comparison of North American and Kashmir Himalayan rhizospheric samples of $C$. canadensis yielded evident differences in the diversity of sequence groups, thereby indicating a shift in AM species composition. In contrast to monotypic stands in Conyza invaded sites in Himalaya, in the native North American sites the species co-occurred with many other plant species. Changes induced by C. canadensis in the AMF spore diversity could possibly be caused through the production of antimicrobials by invasive plants (Vivanco et al. 2004; Stinson et al. 2006), exudation of allelochemicals (Callaway et al. 2004), and/or alteration of quality and quantity of soil nutrients (Vitousek and Walker 1989). A recent study showed that the taxonomic composition and richness of AM fungal communities associated with Trachycarpus fortunei not only varied between the native and introduced ranges but also that sharing a pool of geographically widespread, non-host-specific AM taxa by such a generalist alien plant species facilitates its invasion (Moora et al. 2011). The correspondence analysis indicated relatively closer relationship between the AMF isolates of each biogeographical region than across regions, thereby indicating the influence of specific urban ambience in addition to the other related ecological factors that vary in each of the targeted regions. Notwithstanding that some alien plants can exploit AMF for their invasiveness (Callaway et al. 2004; Shah et al. 2008a, 2008b, Fumanal et al. 2006), invasive species in turn may influence the community structure and diversity of AMF communities negatively (Shah et al. 2010).

\section{Conclusion}

The difference in AMF species composition between Conyza invaded and uninvaded sites in Kashmir Himalaya may be due to differences in aboveground plant composition. We suggest that the long-term evolutionary legacies of AMF-plant interactions in native range of Conyza, as against the relatively short-term and rapid evolutionary relations in non-native regions, might play some role in these differences. These suggestions are, however, tentative, and more evidence from both descriptive and experimental studies is required to assess the role of such evolutionary factors for the differences between AMF species diversity in Conyza rhizosphere in native and non-native regions. Since the evolutionary trends in mycorrhizal mutualisms appear to be much more complex than models and theoretical discussions would suggest (Brundrett, 2002), how invasive plants change the coevolution of native plant-AMF interactions still remains a challenging question. An interesting discourse for the invasion ecologists would be to examine, in a rapid evolution perspective, whether homogenization of diverse soil communities occurs due to urbanizationinduced homogenization of aboveground plant communities. A combined molecular and biogeographical approach through well-replicated field studies, if applied to a larger pool of invasive species from different geographical regions, could potentially lend unprecedented precision to our understanding of the dynamics of invasive plantAMF interactions.

\section{Competing interests}

The authors declare that they have no competing interests.

\section{Authors' contributions}

MAS and ZAR conceived the idea, DPK helped in designing the sampling strategy and data analysis, MEB and MAS carried out the molecular studies, SQ participated in discussions, MAS wrote the first draft and all the authors contributed to manuscript writing.

\section{Acknowledgements}

MAS acknowledge the financial support through internship program by the Department of Foreign Affairs and International Trade (DFAIT) through the Canadian Bureau for International Education (CBIE) at the University Laval, Quebec, Canada. Thanks are due to André Gagné for his help in the lab analysis and Ray Callaway, University of Montana, USA, for his critical appraisal of the earlier draft of this manuscript.

\section{Author details}

${ }^{1}$ Department of Botany, University of Kashmir, Srinagar-190 006, Jammu and Kashmir, India. ${ }^{2}$ Canadian Research Chair in Forest and Environmental Genomics and Institute of Integrative and Systems Biology, Pavillon Marchand, Université laval, Québec G1V 0A6, Canada. ${ }^{3}$ Department of Geography (Landscape Ecology), Humboldt University of Berlin, Rudower Chaussee 16, 12489 Berlin, Germany.

Received: 21 October 2014 Accepted: 21 February 2015

Published online: 17 March 2015

\section{References}

Bonfante P, Genre A (2010) Mechanisms underlying beneficial plant-fungus interactions in mycorrhizal symbiosis. Nature 48:1-11 
Brundrett MC (2002) Coevolution of roots and mycorrhizas of land plants. New Phytol 154:275-304

Burrows R, Pfleger FL (2002) Host plant responses to arbuscular-mycorrhizal fungal inoculum from plots of increasing plant diversity. Plant Soil 240:169-179

Callaway RM, Cipollini D, Barto K, Thelen GC, Hallett SG, Prati D, Stinson K, Klironomos J (2008) Novel weapons: invasive plant suppresses fungal mutualists in America but not in its native Europe. Ecology 89:1043-1055

Callaway RM, Thelen GC, Rodringuez A, Holben WE (2004) Soil biota and exotic plant invasion. Nature 427:731-733

Daniels BA, Skipper HD (1982) Methods for the recovery and quantitative estimation of propagules from soil. In: Schenck NC (ed) Methods and principles of mycorrhizal research. The American Phytopathological Society, St Paul (MN), pp pp 29-35

Dar P, Reshi Z, Shah MA (2015) Roads act as corridors for the spread of alien plant species in the mountainous regions: a case study of Kashmir Valley, India. Tropical Ecol 56(2):183-190

Eom AH, Hartnett DC, Wilson GWT (2000) Host plant species effects on arbuscular mycorrhizal fungal communities in tallgrass prairie. Oecologia 122:435-444

Eppstein MJ, Molofsky J (2007) Invasiveness in plant communities with feedbacks. Ecol Lett 10:253-263

Fierer N, Strickland MS, Liptzin D, Bradford MA, Cleveland CC (2009) Global patterns in belowground communities. Ecol Lett 12:1238-1249

Fumanal B, Plenchette C, Chauvel B, Bretagnolle F (2006) Which role can arbuscular mycorrhizal fungi play in the facilitation of Ambrosia artemisifolia L. invasion in France? Mycorrhiza 17:25-35

Green J, Bohannan BJM (2006) Spatial scaling of microbial biodiversity. Trends Ecol Evol 21:501-507

Grime JP, Macky JM, Hiller SH, Read DJ (1987) Mechanisms of floristic diversity: evidence from microcosm. Nature 328:420-422

Hall TA (1999) BioEdit: a user-friendly biological sequence alignment editor and analysis program for Windows 95/98/NT. Nucleic Acids Sympt Serv 41:95-98

Helgason T, Fitter AH, Young JPW (1999) Molecular diversity of arbuscular mycorrhizal fungi colonizing Hyacinthoides nonscripta (bluebell) in a seminatural stand. Mol Ecol 8:659-666

Husband R, Herre EA, Turner SL, Gallery R, Young JPW (2002) Molecular diversity of arbuscular mycorrhizal fungi and patterns of host association over time and space in a tropical forest. Mol Ecol 11:2669-2678

Lanfranco L, Delpero M, Bonfante P (1999) Intrasporal variability of ribosomal sequences in the endomycorrhizal fungus Gigaspora margarita. Mol Ecol 8:37-45

McKinney ML (2004) Measuring floristic homogenization by non-native plants in North America. Global Ecol Biogeog 13:47-53

McKinney ML, Lockwood JL (1999) Biotic homogenization: a few winners replacing many losers in the next mass extinction. Trends Ecol Evol $14: 450-453$

Moora M, Berger S, Davison J, Öpik M, Bommarco R, Bruelheide H, Kühn, Kunin W, Metsis M, Rortais A, Vanatoa A, Vanatoa E, Stout J, Truusa M, Westphal C, Zobel M, Walther G. (2011) Alien plants associate with widespread generalist arbuscular mycorrhizal fungal taxa: evidence from a continental-scale study using massively parallel 454 sequencing. J Biogeog 38:1305-1317

Mummey DL, Rillig MC (2006) The invasive plant species Centaurea maculosa alters arbuscular mycorrhizal fungal communities in the field. Plant and Soil 288:81-90

Parniske M (2008) Arbuscular mycorrhiza: the mother of plant root endosymbioses. Nature Rev Microbiol 6:763-775

Reinhart KO, Callaway RM (2006) Soil biota and invasive plants. New Phytol 170:445-457

Ronquist F, Huelsenbeck JP (2003) MrBayes3: Bayesian phylogenetic inference under mixed models. Bioinformatics 19:1572-1574

Rooney TP, Wiegmann SM, Rogers DA, Waller DM (2004) Biotic impoverishment and homogenization in unfragmented forest understory communities. Conserv Biol 18:787-798

Ruckli R, Rusterholz H, Baur B (2014) Invasion of an annual exotic plant into deciduous forests suppresses arbuscular mycorrhiza symbiosis and reduces performance of sycamore maple saplings. Forest Ecol Manage 318:285-293

Salisbury E (1942) The reproductive capacity of plants. G. Bell and Sons Ltd., London, UK, p 227
Sanders IR, Alt M, Groppe K, Boller T, Wiemken A (1995) Identification of ribosomal DNA polymorphisms among and within spores of the Glomales: application to studies on the genetic diversity of arbuscular mycorrhizal fungal communities. New Phytol 130:419-427

Scott N, Saggar S, McIntosh P (2001) Biogeochemical impact of Hieracium invasion in New Zealand's grazed tussock grasslands: sustainability implications. Ecol Appl 11:1311-1322

Shah MA, Reshi Z (2007) Invasion by alien Anthemis cotula L. in a biodiversity hotspot: release from native foes or relief from alien friends. Current Sci $92: 1-3$

Shah MA, Reshi Z, Khasa D (2009) Arbuscular mycorrhizas: drivers or passengers of alien plant invasion. Bot Rev 75:397-417

Shah MA, Reshi Z, Rashid I (2008a) Mycorrhizal source and neighbour identity differently influence Anthemis cotula L. invasion in the Kashmir Himalaya, India. Appl Soil Ecol 40:330-337

Shah MA, Reshi Z, Rashid I (2008b) Mycorrhizosphere mediated Chamomile invasion in the Kashmir Himalaya, India. Plant \& Soil 312:219-225

Shah MA, Reshi Z, Rasool N (2010) Plant invasion induces shift in Glomalean spore diversity. Trop Ecol 51(2S):317-323

Shah MA, Callaway RM, Shah T, Houseman GR, Pal RW, Xiao S, Luo W, Rosche C, Reshi ZA, Khasa DP, Chen S (2014) Conyza canadensis suppresses plant diversity in its nonnative ranges but not at home: a transcontinental comparison. New Phytol 202:1286-1296

Shaukat SS, Munir N, Sidique IA (2003) Allelopathic response of Conyza canadensis (L.) Cronquist: a cosmopolitan weed. Asian J Plant Sci 14:1034-1039

Simon L (1996) Specific PCR primers for the identification of endomycorrhizal fungi. In: Methods in molecular biology, Vol. 50: species diagnostic protocols: PCR and other nucleic acid methods, Clapp, J.Pth edn. Humana Press Inc, Totowa NJ

Simon L, Lalonde M, Bruns TD (1992) Specific amplification of 18 S fungal ribosomal genes from vesicular-arbuscular endomycorrhizal fungi colonizing roots. Appl Environ Microbiol 58:291-295

Stéphani FOP, Bérubé JA (2006) Biodiversity of foliar fungal endophytes in white spruce (Picea glauca) from southern Québec. Canad J Bot 84:777-790

Stinson KA, Campbell SA, Powell JR, Wolfe BE, Callaway RM, Thelen GC, Hallett SG, Prati D, Klironomos JN (2006) Invasive plant suppresses the growth of native tree seedlings by disrupting belowground mutualisms. PLoS Biol 4:1-5

Tamura K, Dudley J, Nei M, Kumar S (2007) MEGA4: Molecular Evolutionary Genetics Analysis (MEGA) software version 4.0. Mol Biol Evol 24:1596-1599

Taylor DL, Bruns TD, Hodges SA (2004) Evidence for mycorrhizal races in a cheating orchid. Proc Royal Soc London, B, Biol Sci 271:35-43

Thebaud C, Abbott RJ (1995) Characterization of invasive Conyza species (Asteraceae) in Europe: quantitative trait and isozyme analysis. Am J Bot 82:360-368

Thompson JD, Gibson TJ, Plewniak F, Jeanmougin F, Higgins DG (1997) The CLUSTAL_X windows interface: flexible strategies for multiple sequence alignment aided by quality analysis tools. Nucleic Acids Res 25:4876-4882

Tommerup IC (1992) Methods for the study of the population biology of vesicular-arbuscular mycorrhizal fungi. In: Norris JR, Read DJ, Varma AK (eds) Methods in microbiology, vol 24. Techniques for the study of mycorrhiza, vol 24. Academic, New York, pp pp 23-pp 51

van der Heijden MGA, Klironomos JN, Ursic M, Moutoglis P, Streitwolf-Engel R, Boller T, Wiemken A, Sanders IR (1998) Mycorrhizal fungal diversity determines plant diversity, ecosystem variability and productivity. Nature 396:69-72

Vitousek PM, Walker LR (1989) Biological invasion by Myrica faya in Hawaii-plant demography, nitrogen-fixation, ecosystem effects. Ecol Monogr 59:247-265

Vivanco JM, Bais HP, Stermitz FR, Thelen GC, Callaway RM (2004) Biogeographical variation in community response to root allelochemistry: novel weapons and exotic invasion. Ecol Lett 7:285-292

Weaver SE (2001) The biology of Canadian weeds, 115. Conyza canadensis Can J Plant Sci 81:867-875

Wolfe BE, Klironomos JN (2005) Breaking new ground: soil communities and exotic plant invasion. Bioscience 55:477-487 